\title{
Common fixed point theorems for auxiliary functions with applications in fractional differential equation
}

\author{
Ben Wongsaijai ${ }^{1,2,3}$, Phakdi Charoensawan ${ }^{1,2,3}$, Teeranush Suebcharoen ${ }^{1,2,3}$ and \\ Watchareepan Atiponrat ${ }^{1,2^{*}}$ (D)
}

\author{
"Correspondence: \\ watchareepan.a@cmu.ac.th \\ ${ }^{1}$ Advanced Research Center for \\ Computational Simulation, Chiang \\ Mai University, Chiang Mai, 50200, \\ Thailand \\ ${ }^{2}$ Department of Mathematics, \\ Faculty of Science, Chiang Mai \\ University, Chiang Mai, 50200, \\ Thailand \\ Full list of author information is \\ available at the end of the article
}

\begin{abstract}
In this work, we investigate $h-\phi$ contraction mappings with two metrics endowed with a directed graph which involve auxiliary functions. The achievement allows us to obtain applications for the existence of the solutions for Caputo fractional boundary value problems with the integral boundary condition type. In addition, we also give examples and numerical experiments supporting our main results.
\end{abstract}

Keywords: Fixed point; Common fixed point; Fractional differential equation

\section{Introduction and preliminaries}

The topic of fractional differential equations has been of great interest among mathematicians during the past few decades due to its various applications in science. It is evidenced that fixed point theory has played an important role in improving the understanding of fractional differential equations as this can be seen, for instance, in [1-12].

As being investigated in [11], E. Karapınar considered fixed point theorem using auxiliary functions, and this shed the light on application for fractional differential equations, which has motivated this recent work.

Additionally, in 2008, the notion of fixed point theorem for metric spaces endowed with graphs was introduced by J. Jachymski in [13]. Thenceforth, many researchers have paid their attention to the study of fixed points for mappings on various spaces endowed with graphs, for example, see [14-19]. One of the most important consequences of this generalization is that the famous Banach contraction principle can also be extended into the case of metric spaces endowed with graphs, see [14, 18].

In literature, there are several directions that mathematicians could be exploring fixed point theory. As an illustration, one could consider contractions with Geraghty functions, which are one of the most prominent topics in this field, for example, see [20-29].

Before we move to the next part, there are important definitions and concepts delivered in [13] that should be recalled here, which will be as follows.

(c) The Author(s) 2021. This article is licensed under a Creative Commons Attribution 4.0 International License, which permits use sharing, adaptation, distribution and reproduction in any medium or format, as long as you give appropriate credit to the original author(s) and the source, provide a link to the Creative Commons licence, and indicate if changes were made. The images or other third party material in this article are included in the article's Creative Commons licence, unless indicated otherwise in a credit line to the material. If material is not included in the article's Creative Commons licence and your intended use is not permitted by statutory regulation or exceeds the permitted use, you will need to obtain permission directly from the copyright holder. To view a copy of this licence, visit http://creativecommons.org/licenses/by/4.0/. 
Definition 1 ([13]) Let $(X, d)$ be a metric space, and let $\Delta$ denote the diagonal of $X \times X$. The metric space $(X, d)$ is said to be endowed with a directed graph $G=(V(G), E(G))$ if $G$ is a directed graph such that the vertex set $V(G)$ contains all the elements of $X$, and the edge set $E(G)$ contains $\Delta$ while excluding parallel edges.

Definition $2([28])$ Suppose that $(X, d)$ is a metric space endowed with a directed graph $G=(V(G), E(G))$, and $f, g: X \rightarrow X$ are functions. Let us define the following sets:

$$
\begin{aligned}
& X(f, g):=\{u \in X:(g u, f u) \in E(G)\}, \\
& C(f, g):=\{u \in X: f u=g u\},
\end{aligned}
$$

i.e., $C(f, g)$ is the set of all coincidence points of $f$ and $g$, and

$$
\operatorname{Cm}(f, g):=\{u \in X: f u=g u=u\}
$$

i.e., $\operatorname{Cm}(f, g)$ is the set of all common fixed points of $f$ and $g$.

Lemma 3 ([28]) Let $(X, d)$ be a metric space endowed with a directed graph $G=(V(G)$, $E(G))$, and let $f, g: X \rightarrow X$ be functions. If $C(f, g) \neq \varnothing$, then $X(f, g) \neq \varnothing$.

Definition 4 ([13]) Suppose that $(X, d)$ is a metric space endowed with a directed graph $G=(V(G), E(G))$.

(1) A mapping $f: X \rightarrow X$ is said to be $G$-continuous at $x \in X$ whenever, for any sequence $\left\{x_{n}\right\}$ in $X$ such that $\left(x_{n}, x_{n+1}\right) \in E(G)$ for each $n \in \mathbb{N}$, we have that

$$
\text { if } x_{n} \rightarrow x \in X \text {, then } f x_{n} \rightarrow f x .
$$

Moreover, $f$ is called G-continuous whenever it is G-continuous at every element $x$ of $X$.

(2) The set $E(G)$ is said to have the transitivity property whenever, for all $x, y, z \in X$,

$$
\text { if } \quad(x, z),(z, y) \in E(G), \quad \text { then } \quad(x, y) \in E(G) .
$$

(3) The triple $(X, d, G)$ is said to have the property $A$ whenever, for any sequence $\left\{x_{n}\right\}$ in $X$ such that $x_{n} \rightarrow x \in X$ and $\left(x_{n}, x_{n+1}\right) \in E(G)$ for all $n \in \mathbb{N}$, it is true that $\left(x_{n}, x\right) \in E(G)$ for all $n \in \mathbb{N}$.

On the other hand, interesting results regarding common fixed point theorems for Geraghty type contraction mappings employing the monotone property with two metrics were proved by Martínez-Moreno et al. in 2015 using $d$-compatibility and $g$-uniform continuity, see [29]. This also inspires us to examine metric spaces equipped with two metrics in this work. Before we prove our main results in the next section, let us recall other important definitions as follows. 
Definition 5 ([30]) Let $(X, d)$ be a metric space, and let $f, g: X \rightarrow X$ be functions. Then $f$ and $g$ are said to be $d$-compatible whenever

$$
\lim _{n \rightarrow \infty} d\left(g f x_{n}, f g x_{n}\right)=0
$$

for all sequence $\left\{x_{n}\right\}$ in $X$ with $\lim _{n \rightarrow \infty} f x_{n}=\lim _{n \rightarrow \infty} g x_{n}$.

Definition 6 ([28]) Let $G=(V(G), E(G))$ be a directed graph, and let $f, g: X \rightarrow X$ be functions. We say that $f$ is $g$-edge preserving with respect to $G$ whenever, for each $x \in X$,

if $\quad(g x, g y) \in E(G)$, then $\quad(f x, f y) \in E(G)$.

Definition 7 ([28]) Let $(X, d)$ and $\left(Y, d^{\prime}\right)$ be metric spaces, and let $f: X \rightarrow Y$ and $g: X \rightarrow X$ be functions. We say that $f$ is $g$-Cauchy on $X$ whenever, for any sequence $\left\{x_{n}\right\}$ in $X$ with $\left\{g x_{n}\right\}$ being Cauchy in $(X, d)$, the sequence $\left\{f x_{n}\right\}$ is Cauchy in $\left(Y, d^{\prime}\right)$.

In the next section, we enhance the results in [28] by replacing $\theta-\phi$ contraction mappings with auxiliary functions. This allows us to obtain existence criteria of common fixed points for auxiliary functions with two metrics endowed with a directed graph. Finally, application for nonlinear differential equations and numerical experiments will be provided in the next two parts of this work.

\section{Main results}

In this section, we present new results on existence of common fixed points for auxiliary functions with two metrics endowed with a directed graph. To begin with, let us establish classes of functions which will be considered throughout this work.

Suppose that $\phi:[0, \infty) \rightarrow[0, \infty)$ is a function which has the following properties:

- $\phi$ is an increasing function;

- $\phi$ is a continuous function;

- $\phi(r)=0$ if and only if $r=0$.

From now on, we will denote the set of all such functions $\phi$ satisfying all the above conditions by $\Phi$.

Inspired by [11], the next important class of functions that we shall consider is the class $\mathcal{A}(X)$, where $(X, d)$ is a metric space. This is the class of all auxiliary functions $h: X \times X \rightarrow$ $[0,1]$ such that

$$
\text { if } \lim _{n \rightarrow \infty} h\left(x_{n}, y_{n}\right)=1, \text { then } \lim _{n \rightarrow \infty} d\left(x_{n}, y_{n}\right)=0
$$

for all sequences $\left\{x_{n}\right\}$ and $\left\{y_{n}\right\}$ in $X$.

As a result, we are now in a position to consider a new type of contractions, which is defined as follows.

Definition 8 Let $(X, d)$ be a metric space endowed with a directed graph $G=(V(G), E(G))$, and let $f, g: X \rightarrow X$ be functions. The pair $(f, g)$ will be called an $h$ - $\phi$-contraction with respect to $d$ whenever the following conditions hold:

(1) $f$ is $g$-edge preserving with respect to $G$; 
(2) There exist two functions $h \in \mathcal{A}(X)$ and $\phi \in \Phi$ such that, for all $x, y \in X$ with $(g x, g y) \in E(G)$, we have

$$
\phi(d(f x, f y)) \leq h(g x, g y) \phi(R(g x, g y)),
$$

where $R: X \times X \rightarrow[0, \infty)$ is a function such that, for any $x, y \in X$,

$$
\begin{aligned}
R(g x, g y)= & \max \left\{\frac{d(g x, f x) d(f y, g y)}{d(g x, g y)}, d(g x, g y), d(g x, f x), d(g y, f y),\right. \\
& \left.\frac{d(g x, f y)+d(g y, f x)}{2}\right\} .
\end{aligned}
$$

The above definition allows us to generalize the result in [28] to the case of auxiliary functions. In fact, we are now ready to present and prove our main results. The following theorem involves two metrics as being motivated by [31].

Theorem 9 Let $\left(X, d^{\prime}\right)$ be a complete metric space endowed with a directed graph $G=$ $(V(G), E(G))$, let $d$ be another metric on $X$, and let $f, g: X \rightarrow X$ be functions. Suppose that $(f, g)$ is an h- $\phi$-contraction with respect to $d$, and assume further that the following conditions hold:

(1) $g:\left(X, d^{\prime}\right) \rightarrow\left(X, d^{\prime}\right)$ is a continuous function such that $g(X)$ is $d^{\prime}$-closed;

(2) $f(X) \subseteq g(X)$;

(3) $E(G)$ satisfies the transitivity property;

(4) If $d \nsupseteq d^{\prime}$, assume that $f:(X, d) \rightarrow\left(X, d^{\prime}\right)$ is $g$-Cauchy on $X$;

(5) $f:\left(X, d^{\prime}\right) \rightarrow\left(X, d^{\prime}\right)$ is G-continuous, and $f$ and $g$ are $d^{\prime}$-compatible.

As a consequence, we get that

$$
X(f, g) \neq \varnothing \quad \text { if and only if } \quad C(f, g) \neq \varnothing .
$$

Proof $(\Leftarrow)$ This follows from Lemma 3 .

$(\Rightarrow)$ Suppose that $X(f, g) \neq \varnothing$ and $x_{0} \in X$ with $\left(g x_{0}, f x_{0}\right) \in E(G)$. By the assumption that $f(X) \subseteq g(X)$ and $f\left(x_{0}\right) \in X$, we may construct a sequence $\left\{x_{n}\right\}$ in $X$ such that $g x_{n}=f x_{n-1}$ for each number $n \in \mathbb{N}$. If it is the case that $g x_{n_{0}}=g x_{n_{0}-1}$ for some $n_{0} \in \mathbb{N}$, then $x_{n_{0}-1}$ must be a coincidence point of $f$ and $g$. As a result, we may assume now that, for every $n \in \mathbb{N}$, $g x_{n} \neq g x_{n-1}$.

Because $\left(g x_{0}, f x_{0}\right)=\left(g x_{0}, g x_{1}\right) \in E(G)$ and the function $f$ is $g$-edge preserving with respect to $G$, it is true that $\left(f x_{0}, f x_{1}\right)=\left(g x_{1}, g x_{2}\right) \in E(G)$. By mathematical induction, we receive $\left(g x_{n-1}, g x_{n}\right) \in E(G)$ for any $n \in \mathbb{N}$. Since $(f, g)$ is an $h$ - $\phi$-contraction with respect to $d$, for each $n \geq 0$,

$$
\begin{aligned}
\phi\left(d\left(g x_{n+1}, g x_{n+2}\right)\right) & =\phi\left(d\left(f x_{n}, f x_{n+1}\right)\right) \\
& \leq h\left(g x_{n}, g x_{n+1}\right) \phi\left(R\left(g x_{n}, g x_{n+1}\right)\right) \\
& \leq \phi\left(R\left(g x_{n}, g x_{n+1}\right)\right) .
\end{aligned}
$$

Also, a direct calculation shows that

$$
R\left(g x_{n}, g x_{n+1}\right)=\max \left\{d\left(g x_{n}, g x_{n+1}\right), d\left(g x_{n}, f x_{n}\right), d\left(g x_{n+1}, f x_{n+1}\right),\right.
$$




$$
\begin{aligned}
& \left.\frac{d\left(g x_{n}, f x_{n+1}\right)+d\left(g x_{n+1}, f x_{n}\right)}{2}\right\} \\
= & \max \left\{d\left(g x_{n}, g x_{n+1}\right), d\left(g x_{n+1}, g x_{n+2}\right), \frac{d\left(g x_{n}, g x_{n+2}\right)}{2}\right\} \\
= & \max \left\{d\left(g x_{n}, g x_{n+1}\right), d\left(g x_{n+1}, g x_{n+2}\right)\right\} .
\end{aligned}
$$

Then $R\left(g x_{n}, g x_{n+1}\right)=d\left(g x_{n}, g x_{n+1}\right)$ or $R\left(g x_{n}, g x_{n+1}\right)=d\left(g x_{n+1}, g x_{n+2}\right)$. In both cases, we will show that $\lim _{n \rightarrow \infty} d\left(g x_{n}, g x_{n+1}\right)=0$.

If $R\left(g x_{n}, g x_{n+1}\right)=d\left(g x_{n+1}, g x_{n+2}\right)$, then by inequality (1) we have

$$
\phi\left(d\left(g x_{n+1}, g x_{n+2}\right)\right) \leq h\left(g x_{n}, g x_{n+1}\right) \phi\left(d\left(g x_{n+1}, g x_{n+2}\right)\right) \leq \phi\left(d\left(g x_{n+1}, g x_{n+2}\right)\right)
$$

for each $n \geq 0$. By our assumption, $g x_{n+1} \neq g x_{n+2}$ so $d\left(g x_{n+1}, g x_{n+2}\right)>0$. As a consequence, $\phi\left(d\left(g x_{n+1}, g x_{n+2}\right)\right)>0$. Hence, $\lim _{n \rightarrow \infty} h\left(g x_{n}, g x_{n+1}\right)=1$. Thus, we get $\lim _{n \rightarrow \infty} d\left(g x_{n}, g x_{n+1}\right)=$ 0 .

If $R\left(g x_{n}, g x_{n+1}\right)=d\left(g x_{n}, g x_{n+1}\right)$, then by similar argument as in the previous case we receive

$$
\phi\left(d\left(g x_{n+1}, g x_{n+2}\right)\right) \leq h\left(g x_{n}, g x_{n+1}\right) \phi\left(d\left(g x_{n}, g x_{n+1}\right)\right) \leq \phi\left(d\left(g x_{n}, g x_{n+1}\right)\right) .
$$

So, we get that $\left\{\phi\left(d\left(g x_{n}, g x_{n+1}\right)\right)\right\}$ is a nonincreasing sequence, which implies that the sequence $\left\{d\left(g x_{n}, g x_{n+1}\right)\right\}$ must be nonincreasing by the definition of $\phi$. Since the later sequence is bounded below, it becomes a convergent sequence. Suppose on the contrary that $\lim _{n \rightarrow \infty} d\left(g x_{n}, g x_{n+1}\right)>0$. Thus, $\lim _{n \rightarrow \infty} \phi\left(d\left(g x_{n}, g x_{n+1}\right)\right)>0$ by the property of $\phi$. By (2), it is true that

$$
1=\lim _{n \rightarrow \infty} \frac{\phi\left(d\left(g x_{n+1}, g x_{n+2}\right)\right)}{\phi\left(d\left(g x_{n}, g x_{n+1}\right)\right)} \leq \lim _{n \rightarrow \infty} h\left(g x_{n}, g x_{n+1}\right) \leq 1 .
$$

Therefore, $\lim _{n \rightarrow \infty} h\left(g x_{n}, g x_{n+1}\right)=1$. By the definition of auxiliary functions, $\lim _{n \rightarrow \infty} d\left(g x_{n}, g x_{n+1}\right)=0$, which contradicts the assumption. So, the equation $\lim _{n \rightarrow \infty} h\left(g x_{n}, g x_{n+1}\right)=0$ must be true.

Next, we will show that the sequence $\left\{g x_{n}\right\}$ must be Cauchy. Suppose on the contrary that $\left\{g x_{n}\right\}$ is not Cauchy. Therefore, there is $\epsilon>0$ such that, for all $k \in \mathbb{N}$, there are $n(k), m(k) \in \mathbb{N}$ such that $n(k)>m(k) \geq k$ with the property that $n(k)$ being the smallest number satisfies the properties as follows:

$$
d\left(g x_{n(k)}, g x_{m(k)}\right) \geq \epsilon \quad \text { and } \quad d\left(g x_{n(k)-1}, g x_{m(k)}\right)<\epsilon .
$$

This implies

$$
\begin{aligned}
\epsilon & \leq d\left(g x_{m(k)}, g x_{n(k)}\right) \\
& \leq d\left(g x_{m(k)}, g x_{n(k)-1}\right)+d\left(g x_{n(k)-1}, g x_{n(k)}\right) \\
& <\epsilon+d\left(g x_{n(k)-1}, g x_{n(k)}\right) .
\end{aligned}
$$


Taking $k \rightarrow \infty$ in the above conclusion and using $\lim _{n \rightarrow \infty} d\left(g x_{n}, g x_{n+1}\right)=0$, we receive

$$
\lim _{k \rightarrow \infty} d\left(g x_{m(k)}, g x_{n(k)}\right)=\epsilon>0 .
$$

Because $E(G)$ has the transitivity property, we obtain that $\left(g x_{m(k)}, g x_{n(k)}\right) \in E(G)$ for every $k \in \mathbb{N}$. As a consequence,

$$
\begin{aligned}
\phi\left(d\left(g x_{m(k)+1}, g x_{n(k)+1}\right)\right) & =\phi\left(d\left(f x_{m(k)}, f x_{n(k)}\right)\right) \\
& \leq h\left(g x_{m(k)}, g x_{n(k)}\right) \phi\left(R\left(g x_{m(k)}, g x_{n(k)}\right)\right),
\end{aligned}
$$

where

$$
\begin{aligned}
R\left(g x_{m(k)}, g x_{n(k)}\right)= & \max \left\{\frac{d\left(g x_{m(k)}, f x_{m(k)}\right) d\left(g x_{n(k)}, f x_{n(k)}\right)}{d\left(g x_{m(k)}, g x_{n(k)}\right)},\right. \\
& d\left(g x_{m(k)}, g x_{n(k)}\right), d\left(g x_{m(k)}, f x_{m(k)}\right), d\left(g x_{n(k)}, f x_{n(k)}\right), \\
& \left.\frac{d\left(g x_{m(k)}, f x_{n(k)}\right)+d\left(g x_{n(k)}, f x_{m(k)}\right)}{2}\right\} \\
= & \max \left\{\frac{d\left(g x_{m(k)}, g x_{m(k)+1}\right) d\left(g x_{n(k)}, g x_{n(k)+1}\right)}{d\left(g x_{m(k)}, g x_{n(k)}\right)},\right. \\
& d\left(g x_{m(k)}, g x_{n(k)}\right), d\left(g x_{m(k)}, g x_{m(k)+1}\right), d\left(g x_{n(k)}, g x_{n(k)+1}\right), \\
& \left.\frac{d\left(g x_{m(k)}, g x_{n(k)+1}\right)+d\left(g x_{n(k)}, g x_{m(k)+1}\right)}{2}\right\} \\
\leq & \max \left\{\frac{d\left(g x_{m(k)}, g x_{m(k)+1}\right) d\left(g x_{n(k)}, g x_{n(k)+1}\right)}{d\left(g x_{m(k)}, g x_{n(k)}\right)},\right. \\
& d\left(g x_{m(k)}, g x_{n(k)}\right), d\left(g x_{m(k)}, g x_{m(k)+1}\right), d\left(g x_{n(k)}, g x_{n(k)+1}\right), \\
& \frac{d\left(g x_{m(k)}, g x_{n(k)}\right)+d\left(g x_{n(k)}, g x_{n(k)+1}\right)}{2} \\
& \left.+\frac{d\left(g x_{m(k)}, g x_{n(k)}\right)+d\left(g x_{n(k)}, g x_{m(k)+1}\right)}{2}\right\} . \\
& \\
& \\
&
\end{aligned}
$$

Since $\lim _{n \rightarrow \infty} d\left(g x_{n}, g x_{n+1}\right)=0$, letting $k \rightarrow \infty$ in the above inequality implies that

$$
\lim _{k \rightarrow \infty} R\left(g x_{m(k)}, g x_{n(k)}\right)=\lim _{k \rightarrow \infty} d\left(g x_{m(k)}, g x_{n(k)}\right)=\epsilon>0 .
$$

By inequality (4) and the above fact, we get

$$
1=\lim _{k \rightarrow \infty} \frac{\phi\left(d\left(g x_{m(k)+1}, g x_{n(k)+1}\right)\right)}{\phi\left(d\left(g x_{m(k)}, g x_{n(k)}\right)\right)} \leq \lim _{k \rightarrow \infty} h\left(g x_{m(k)}, g x_{n(k)}\right) \leq 1 .
$$

As a result, $\lim _{k \rightarrow \infty} h\left(g x_{m(k)}, g x_{n(k)}\right)=1$. Thus, $\lim _{k \rightarrow \infty} d\left(g x_{m(k)}, g x_{n(k)}\right)=0$, which contradicts (3). So, it must be true that $\left\{g x_{n}\right\}$ is Cauchy in the metric space $(X, d)$.

In the next part, we prove that $\left\{g x_{n}\right\}$ is also Cauchy in the metric space $\left(X, d^{\prime}\right)$.

When $d \geq d^{\prime}$, the proof is trivial. Therefore, we consider the case $d \nsupseteq d^{\prime}$. Let $\varepsilon>0$. Because $\left\{g x_{n}\right\}$ is Cauchy in $(X, d)$ and the function $f$ is $g$-Cauchy on $X$, we obtain that $\left\{x_{n}\right\}$ 
is Cauchy in the metric space $\left(X, d^{\prime}\right)$. So, there is a number $N_{0} \in \mathbb{N}$ such that

$$
d^{\prime}\left(g x_{n+1}, g x_{m+1}\right)=d^{\prime}\left(f x_{n}, f x_{m}\right)<\varepsilon
$$

for all numbers $n, m \geq N_{0}$. Hence, the sequence $\left\{g x_{n}\right\}$ is Cauchy in $\left(X, d^{\prime}\right)$.

Next, the fact that $g(X)$ is a $d^{\prime}$-closed subset of $\left(X, d^{\prime}\right)$, which is complete, implies the existence of $u=g x \in g(X)$, which satisfies

$$
\lim _{n \rightarrow \infty} g x_{n}=\lim _{n \rightarrow \infty} f x_{n}=u .
$$

In addition, using the fact that $f:\left(X, d^{\prime}\right) \rightarrow\left(X, d^{\prime}\right)$ is a $G$-continuous function such that $f$ and $g$ are $d^{\prime}$-compatible, we arrive at the conclusion that

$$
\lim _{n \rightarrow \infty} d^{\prime}\left(g f x_{n}, f g x_{n}\right)=0
$$

Finally, consider

$$
d^{\prime}(g u, f u) \leq d^{\prime}\left(g u, g f x_{n}\right)+d^{\prime}\left(g f x_{n}, f g x_{n}\right)+d^{\prime}\left(f g x_{n}, f u\right) .
$$

Taking $n \rightarrow \infty$, we obtain that $d^{\prime}(g u, f u)=0$ because of (5), the continuity of $g$, and the fact that $f$ is $G$-continuous. Therefore, $g u=f u$, which implies that $u$ is a coincidence point of $f$ and $g$.

In our next theorem, we consider the case when the two metrics $d$ and $d^{\prime}$ coincide.

Theorem 10 Let $(X, d)$ be a complete metric space endowed with a directed graph $G=$ $(V(G), E(G))$, and let $f, g: X \rightarrow X$ be functions such that $(f, g)$ is an h- $\phi$-contraction with respect to $d$. Assume further that the following conditions hold:

(1) $g$ is a continuous function such that $g(X)$ is closed;

(2) $f(X) \subseteq g(X)$;

(3) $E(G)$ attains the transitivity property;

(4) At least one of the following conditions is true:

(a) $f$ is G-continuous, and $f$ and $g$ are d-compatible;

(b) $(X, d, G)$ has the property $A$.

As a consequence, we get that

$$
X(f, g) \neq \varnothing \quad \text { if and only if } \quad C(f, g) \neq \varnothing .
$$

Proof From the proof of Theorem 9, it suffices to consider the only if case together with the assumption that (b) of condition (4) above is true. We will adopt all the notations from the proof of Theorem 9. By the fact that the sequence $\left\{g x_{n}\right\}$ is Cauchy and $g(X)$ is a closed subset of $X$, there is an element $u \in X$ with

$$
\lim _{n \rightarrow \infty} g x_{n}=g u=\lim _{n \rightarrow \infty} f x_{n} .
$$

We claim that $u$ must be a coincidence point of $f$ and $g$. Suppose on the contrary that $u$ is not a coincidence point of $f$ and $g$. Therefore, $f u \neq g u$ and hence $d(f u, g u)>0$. 
Then $\left(g x_{n}, g u\right) \in E(G)$ for every $n \in \mathbb{N}$ because the triple $(X, d, G)$ has the property $A$. Also,

$$
d(g u, f u) \leq d\left(g u, f x_{n(k)}\right)+d\left(f x_{n(k)}, f u\right) .
$$

As a result,

$$
d(g u, f u)-d\left(g u, f x_{n(k)}\right) \leq d\left(f x_{n(k)}, f u\right) .
$$

In fact, the definition of $\phi$ implies that

$$
\begin{aligned}
\phi\left(d(g u, f u)-d\left(g u, f x_{n(k)}\right)\right) & \leq \phi\left(d\left(f x_{n(k)}, f u\right)\right) \\
& \leq h\left(g x_{n(k)}, g u\right) \phi\left(R\left(g x_{n(k)}, g u\right)\right),
\end{aligned}
$$

where

$$
\begin{aligned}
R\left(g x_{n(k)}, g u\right)= & \max \left\{\frac{d\left(g x_{n(k)}, f x_{n(k)}\right) d(g u, f u)}{d\left(g x_{n(k)}, g u\right)}, d\left(g x_{n(k)}, g u\right),\right. \\
& \left.d\left(g x_{n(k)}, f x_{n(k)}\right), d(g u, f u), \frac{d\left(g x_{n(k)}, f u\right)+d\left(g u, f x_{n(k)}\right)}{2}\right\} .
\end{aligned}
$$

Letting $k \rightarrow \infty$ in the above equation and using (6), we get

$$
\lim _{k \rightarrow \infty} R\left(g x_{n(k)}, g u\right)=d(g u, f u)>0 .
$$

Then, taking $k \rightarrow \infty$ in (7) gives us that $\lim _{k \rightarrow \infty} h\left(g x_{n(k)}, g u\right)=1$. This implies $d(g u, f u)=$ $\lim _{k \rightarrow \infty} d\left(g x_{n(k)}, g u\right)=0$, which is a contradiction. Hence, $f u=g u$ and we can deduce that $f$ and $g$ have $u$ as one of their coincidence points.

We may obtain a stronger result about the existence of a common fixed point by assuming an extra condition as in the theorem below.

Theorem 11 Let us adopt all the notations and conditions that appeared in Theorem 9. Furthermore, assume in addition that

(6) For any $x, y \in C(f, g)$ with $g x \neq g y$, it is true that $(g x, g y) \in E(G)$.

As a consequence, we get that

$$
X(f, g) \neq \varnothing \quad \text { if and only if } \operatorname{Cm}(f, g) \neq \varnothing .
$$

Proof From the proof of Theorem 9, it suffices to consider the only if case together with the assumption that condition (6) above is true. By Theorem 9, there is an element $x \in X$ such that $g x=f x$.

To begin with, suppose that $y \in X$ is also a coincidence point, i.e., $g y=f y$. We will show that $g x=g y$. To see this, suppose on the contrary that $g x \neq g y$. By condition (6) above, $(g x, g y) \in E(G)$, which implies

$$
\phi(d(f x, f y)) \leq h(g x, g y) \phi(R(g x, g y)) \leq \phi(R(g x, g y))=\phi(d(f x, f y)) .
$$

Thus, $h(g x, g y)=1$ by the property of $\phi$. As a result, $g x=g y$. 
Next, set $x_{0}=x$ and use condition (2) in Theorem 9 to construct a sequence $\left\{x_{n}\right\}$ such that $g x_{n}=f x_{n-1}$ for any $n \in \mathbb{N}$. In particular, since $x$ is a coincidence point, we may assume it is the case that $x_{n}=x$ so $g x_{n}=f x$ for every $n \in \mathbb{N}$.

Then, let $z=g x$ so that $g z=g g x=g f x$. Note also that $g x_{n}=f x=f x_{n-1}$ for each $n \in \mathbb{N}$. Therefore,

$$
\lim _{n \rightarrow \infty} f x_{n}=\lim _{n \rightarrow \infty} g x_{n}=f x
$$

in $\left(X, d^{\prime}\right)$. Furthermore,

$$
\lim _{n \rightarrow \infty} d^{\prime}\left(g f x_{n}, f g x_{n}\right)=0,
$$

since $f$ and $g$ are $d^{\prime}$-compatible. This means $g f x=f g x$. Hence, $g z=g f x=f g x=f z$ so $z \in$ $C(f, g)$. By the above proof, $f z=g z=g x=z$. Thus, $z \in C m(f, g)$.

In the last part of this section, we give an example supporting our main results.

Example 1 Suppose that $X=[0, \infty) \subseteq \mathbb{R}$, and $d, d^{\prime}: X \times X \rightarrow[0, \infty)$ are such that

$$
d(x, y)=|x-y| \quad \text { and } \quad d^{\prime}(x, y)=L|x-y|
$$

for all $x, y \in X$, where $L \in(1, \infty)$ is a constant. It can be easily checked that $d$ and $d^{\prime}$ are metrics. Furthermore, by the way we define our metrics, we clearly get that $d<d^{\prime}$.

Next, suppose

$$
E(G)=\{(x, y): x=y \text { or } x, y \in[0,1] \text { with } x \leq y\} .
$$

In addition, let $f: X \rightarrow X$ and $g: X \rightarrow X$ be given by

$$
g x=x^{2} \quad \text { and } \quad f x=\ln \left(1+\frac{x^{2}}{4}\right)
$$

for each $x \in X$.

We will prove that requirements (1) and (2) for the pair $(f, g)$ to be an $h$ - $\phi$-contraction with respect to $d$ are true.

First, let $(g x, g y) \in E(G)$. Observe that if $x=y$, then $(f x, f y) \in E(G)$. On the other hand, if $(g x, g y) \in E(G)$ and $g x \leq g y$, then $g x=x^{2}, g y=y^{2} \in[0,1]$ and $x^{2}=g x \leq g y=y^{2}$. Therefore, $f x=\ln \left(1+\frac{x^{2}}{4}\right) \leq \ln \left(1+\frac{y^{2}}{4}\right)=f y$ and $f x, f y \in[0,1]$. Thus, $(f x, f y) \in E(G)$.

Second, set $\phi(t)=\frac{t}{4}$, and define $h: X \times X \rightarrow[0,1]$ by the following equation:

$$
h(x, y)= \begin{cases}\frac{4 \ln \left(1+\frac{|x-y|}{4}\right)}{|x-y|} & \text { if }|x-y|>0 \\ 0 & \text { if }|x-y|=0\end{cases}
$$

It is straightforward to prove that $\phi \in \Phi$ and $h \in \mathcal{A}(X)$. Next, let $x, y \in X$ such that $(g x, g y) \in$ $E(G)$. If $g x=g y$, then $x=y$ so that requirement (2) is satisfied. On the other hand, if $g x=x^{2}$, 
$g y=y^{2} \in[0,1]$ and $x^{2}=g x<g y=y^{2}$, then it follows that

$$
\begin{aligned}
\phi(d(f x, f y)) & =\frac{d(f x, f y)}{4}=\frac{\left|\ln \left(1+\frac{x^{2}}{4}\right)-\ln \left(1+\frac{y^{2}}{4}\right)\right|}{4} \\
& =\frac{\ln \left(1+\frac{y^{2}}{4}\right)-\ln \left(1+\frac{x^{2}}{4}\right)}{4} \\
& =\frac{\ln \left(\frac{1+\frac{y^{2}}{4}}{1+\frac{x^{2}}{4}}\right.}{4} \\
& =\frac{\ln \left(1+\frac{y^{2}}{1+\frac{x^{2}}{4}}\right)}{4} \\
& \leq \frac{\ln \left(1+\left|\frac{x^{2}}{4}-\frac{y^{2}}{4}\right|\right)}{4} \\
& =\frac{4 \ln \left(1+\frac{1}{4}\left|x^{2}-y^{2}\right|\right)}{\left|x^{2}-y^{2}\right|} \frac{\left|x^{2}-y^{2}\right|}{4} \\
& =\frac{4 \ln \left(1+\frac{1}{4} d(g x, g y)\right)}{d(g x, g y)} \phi(d(g x, g y)) \\
& h(g x, g y) \phi(d(g x, g y)) .
\end{aligned}
$$

Therefore, condition (2) holds for the pair $(f, g)$.

In the last part of this example, we will prove that conditions (1)-(5) of Theorem 9 are satisfied.

(1) $g:\left(X, d^{\prime}\right) \rightarrow\left(X, d^{\prime}\right)$ is clearly a continuous function such that $g(X)=[0, \infty)$ is also $d^{\prime}$-closed;

(2) It is not hard to see that $f(X)=g(X)=X$;

(3) $E(G)$ has the transitivity property;

(4) From the fact that $d<d^{\prime}$, we will show that $f:(X, d) \rightarrow\left(X, d^{\prime}\right)$ is $g$-Cauchy. Given $\epsilon>0$ and a sequence $\left\{x_{n}\right\}$ in $X$ with $\left\{g x_{n}\right\}$ being Cauchy in $(X, d)$, there is $N \in \mathbb{N}$ such that $d\left(g x_{n}, g x_{m}\right)<\frac{\epsilon}{L}$ for all $n, m \geq N$. Therefore,

$$
\begin{aligned}
d^{\prime}\left(f x_{n}, f x_{m}\right) & =L\left|f x_{n}-f y_{m}\right| \\
& =L\left|\ln \left(1+\frac{\left(x_{n}\right)^{2}}{4}\right)-\ln \left(1+\frac{\left(x_{m}\right)^{2}}{4}\right)\right| \\
& =L\left|\ln \left(\frac{1+\frac{\left(x_{m}\right)^{2}}{4}}{1+\frac{\left(x_{n}\right)^{2}}{4}}\right)\right| \\
& =L\left|\ln \left(1+\frac{\frac{\left(x_{m}\right)^{2}}{4}-\frac{\left(x_{n}\right)^{2}}{4}}{1+\frac{\left(x_{n}\right)^{2}}{4}}\right)\right| \\
& \leq L\left[\ln \left(1+\left|\frac{\left(x_{n}\right)^{2}}{4}-\frac{\left(x_{m}\right)^{2}}{4}\right|\right)\right] \\
& \leq L\left[\frac{4 \ln \left(1+\frac{1}{4}\left|\left(x_{n}\right)^{2}-\left(x_{m}\right)^{2}\right|\right)}{\left|\left(x_{n}\right)^{2}-\left(x_{m}\right)^{2}\right|}\left|\left(x_{n}\right)^{2}-\left(x_{m}\right)^{2}\right|\right]
\end{aligned}
$$




$$
\begin{aligned}
& <L\left|\left(x_{n}\right)^{2}-\left(x_{m}\right)^{2}\right| \\
& =L d\left(g x_{n}, g x_{m}\right) \\
& <L\left(\frac{\epsilon}{L}\right) \\
& =\epsilon .
\end{aligned}
$$

This amounts to saying that $f:(X, d) \rightarrow\left(X, d^{\prime}\right)$ is $g$-Cauchy;

(5) $f:\left(X, d^{\prime}\right) \rightarrow\left(X, d^{\prime}\right)$ is clearly $G$-continuous. Moreover, $f$ and $g$ are $d^{\prime}$-compatible since for any sequence $\left\{x_{n}\right\}$ in $X$ with

$$
\lim _{n \rightarrow \infty} g x_{n}=\lim _{n \rightarrow \infty} f x_{n}=x
$$

it results that $\ln \left(1+\frac{x}{4}\right)=x$. This implies $x=0$. Also, as $n \rightarrow \infty$,

$$
d^{\prime}\left(g f x_{n}, f g x_{n}\right)=L\left|\left(\ln \left(1+\frac{\left(x_{n}\right)^{2}}{2}\right)\right)^{2}-\ln \left(1+\frac{\left(x_{n}\right)^{4}}{2}\right)\right| \rightarrow 0 .
$$

Finally, observe that $(g 0, f 0)=(0,0) \in E(G)$ so $X(f, g)$ is nonempty. By Theorem 9, $C(f, g) \neq \varnothing$. In fact, it can be easily seen that $0 \in C(f, g)$.

\section{Application to nonlinear fractional differential equations with nonlocal boundary conditions}

In this section, we discuss the application of our results to study the existence of the solutions for Caputo fractional boundary value problems of order $\alpha \in(n-1, n]$, where $n \geq 2$ is an integer, with the integral boundary condition type. Before going through the existence results, we need to recall the definition of the Caputo fractional derivative and related concepts.

Let $\alpha$ be a positive real number. For a continuous function $u(t)$, the Caputo derivative of fractional order $\alpha$ is defined as

$$
{ }^{c} D^{\alpha} u=I^{\lceil\alpha\rceil-\alpha} D^{\lceil\alpha\rceil} u,
$$

where $\lceil\alpha\rceil$ is the smallest integer which is greater than or equal to $\alpha$, and $I^{\alpha}$ is the Riemann-Liouville integral operator of order $\alpha \geq 0$ defined by

$$
I^{\alpha} u(t)=\frac{1}{\Gamma(\alpha)} \int_{0}^{t}(t-s)^{\alpha-1} u(s) d s
$$

Note that, in the case of $\alpha=0$, the operator $I^{0}$ is referred to as the identity operator. Moreover, the gamma function $\Gamma$ is defined by $\Gamma(\alpha)=\int_{0}^{\infty} t^{\alpha-1} e^{-t} d t$.

Now, we are in a position to consider the nonlinear fractional differential equation in the following form:

$$
\left({ }^{c} D^{\alpha} y\right)(t)=f(t, y(t)), \quad t \in[0,1], n-1<\alpha \leq n
$$


with the boundary conditions

$$
y(0)=y^{\prime}(0)=\cdots=y^{(n-2)}(0)=0 \quad \text { and } \quad y(1)=\int_{0}^{\eta} y(s) d s,
$$

where $\eta \in[0,1]$ and $f:[0,1] \times \mathbb{R} \rightarrow \mathbb{R}$.

Next, we consider some auxiliary results that will be used to prove our main theorems. It is well known that the initial value problem (BVP) (8)-(9) is equivalent to the Volterra integral equation in specific type. In order to obtain the particular Volterra integral equation corresponding to BVP (8)-(9), we observe that the solution $y \in C[0,1]$ of equation (8) is

$$
y(t)=a_{0}+a_{1} t+a_{2} t^{2}+\cdots+a_{n-1} t^{n-1}+\frac{1}{\Gamma(\alpha)} \int_{0}^{t}(t-s)^{\alpha-1} f(s, y(s)) d s,
$$

where $a_{0}, a_{1}, \ldots, a_{n-1} \in \mathbb{R}$. By using the boundary conditions $y(0)=y^{\prime}(0)=\cdots=y^{(n-2)}(0)=$ 0 , we have $a_{0}=a_{1}=\cdots=a_{n-2}=0$. Therefore, the solution is reduced to $y(t)=a_{n-1} t^{n-1}+$ $I^{\alpha} f(t, y(t))$. To possess the coefficient $a_{n-1}$, we apply the boundary condition $y(1)=$ $\int_{0}^{\eta} y(s) d s$. This yields

$$
y(1)=a_{n-1}+\frac{1}{\Gamma(\alpha)} \int_{0}^{1}(1-s)^{\alpha-1} f(s, y(s)) d s,
$$

which is equivalent to

$$
\begin{aligned}
a_{n-1}= & \int_{0}^{\eta} y(s) d s-\frac{1}{\Gamma(\alpha)} \int_{0}^{1}(1-s)^{\alpha-1} f(s, y(s)) d s \\
= & \int_{0}^{\eta}\left(a_{n-1} s^{n-1}+\frac{1}{\Gamma(\alpha)} \int_{0}^{s}(s-\tau)^{\alpha-1} f(\tau, y(\tau)) d \tau\right) d s \\
& -\frac{1}{\Gamma(\alpha)} \int_{0}^{1}(1-s)^{\alpha-1} f(s, y(s)) d s \\
= & \frac{\eta^{n}}{n} a_{n-1}+\frac{1}{\Gamma(\alpha)} \int_{0}^{\eta} \int_{0}^{s}(s-\tau)^{\alpha-1} f(\tau, y(\tau)) d \tau d s \\
& -\frac{1}{\Gamma(\alpha)} \int_{0}^{1}(1-s)^{\alpha-1} f(s, y(s)) d s .
\end{aligned}
$$

Hence,

$$
\begin{aligned}
a_{n-1}= & \frac{n}{\left(n-\eta^{n}\right) \Gamma(\alpha)} \int_{0}^{\eta} \int_{0}^{s}(s-\tau)^{\alpha-1} f(\tau, y(\tau)) d \tau d s \\
& -\frac{n}{\left(n-\eta^{n}\right) \Gamma(\alpha)} \int_{0}^{1}(1-s)^{\alpha-1} f(s, y(s)) d s .
\end{aligned}
$$

Substituting $a_{n-1}$ in $y(t)$, we obtain the solution of BVP (8)-(9) as the solution of the Volterra integral equation in the following form:

$$
y(t)=\frac{n t^{n-1}}{\left(n-\eta^{n}\right) \Gamma(\alpha)} \int_{0}^{\eta} \int_{0}^{s}(s-\tau)^{\alpha-1} f(\tau, y(\tau)) d \tau d s
$$




$$
\begin{aligned}
& -\frac{n t^{n-1}}{\left(n-\eta^{n}\right) \Gamma(\alpha)} \int_{0}^{1}(1-s)^{\alpha-1} f(s, y(s)) d s \\
& +\frac{1}{\Gamma(\alpha)} \int_{0}^{t}(t-s)^{\alpha-1} f(s, y(s)) d s .
\end{aligned}
$$

As a common technique, we introduce the integral operator in order to find a suitable fixed point problem with $T: C[0,1] \rightarrow C[0,1]$ defined by

$$
\begin{aligned}
T(y)(t)= & \frac{n t^{n-1}}{\left(n-\eta^{n}\right) \Gamma(\alpha)} \int_{0}^{\eta} \int_{0}^{s}(s-\tau)^{\alpha-1} f(\tau, y(\tau)) d \tau d s \\
& -\frac{n t^{n-1}}{\left(n-\eta^{n}\right) \Gamma(\alpha)} \int_{0}^{1}(1-s)^{\alpha-1} f(s, y(s)) d s \\
& +\frac{1}{\Gamma(\alpha)} \int_{0}^{t}(t-s)^{\alpha-1} f(s, y(s)) d s .
\end{aligned}
$$

Here, we note that the solution of BVP (8)-(9) is given by $T y=y$. To achieve the existence of a solution, let the metric space $\left(C[0,1],\|\cdot\|_{\infty}\right)$ be endowed with a directed graph $G=$ $(V(G), E(G))$. In addition, let us consider the following conditions, which will be assumed later.

$\left(\mathrm{H}_{1}\right)$ For all $t \in[0,1]$ and for all $u, v \in C[0,1]$ with $(u, v) \in E(G)$, there exists $\phi \in \Phi$ with $\phi(r)<r$ for all $r \in(0,1]$ such that

$$
|f(t, u(t))-f(t, v(t))| \leq K_{1} \phi(|u(t)-v(t)|)
$$

where the constant $K_{1}$ satisfies

$$
K_{1} \leq \frac{\left(n-\eta^{n}\right) \Gamma(\alpha+2)}{n \eta^{\alpha+1}+(\alpha+1)\left(2 n-\eta^{n}\right)}
$$

$\left(\mathrm{H}_{2}\right)$ There exists $u_{0} \in C[0,1]$ such that $\left(u_{0}, T u_{0}\right) \in E(G)$;

$\left(\mathrm{H}_{3}\right)$ For all $u, v \in C[0,1]$,

$$
(u, v) \in E(G) \quad \text { implies } \quad(T u, T v) \in E(G)
$$

$\left(\mathrm{H}_{4}\right)$ For any sequence $\left\{u_{n}\right\}$ in $C[0,1]$ such that $u_{n} \rightarrow u \in C[0,1]$ and $\left(u_{n}, u_{n+1}\right) \in E(G)$ for all $n \in \mathbb{N}$, it is true that $\left(u_{n}, u\right) \in E(G)$ for all $n \in \mathbb{N}$;

$\left(\mathrm{H}_{5}\right)$ For all $u, v, w \in C[0,1]$,

$$
(u, v),(v, w) \in E(G) \quad \text { implies } \quad(u, w) \in E(G) .
$$

It is worth mentioning that the term $K_{1}$ in condition $\left(\mathrm{H}_{1}\right)$ is well defined due to the positivity of each term. Next, we prove the following result.

Theorem 12 Suppose that conditions $\left(H_{1}\right)-\left(H_{5}\right)$ hold. Then $T$ has at least one fixed point $u^{*} \in C[0,1]$, which means that $B V P(8)-(9)$ has at least one solution $u^{*} \in C[0,1]$.

Proof It is not hard to see that $\left(\mathrm{H}_{3}\right)$ implies $T$ is $g$-edge preserving with respect to $G$, where $g: C[0,1] \rightarrow C[0,1]$ is the identity map. Thenceforth, we will omit $g$ in our proof. 
In addition, $\left(\mathrm{H}_{4}\right)$ implies that $\left(C[0,1],\|\cdot\|_{\infty}, G\right)$ has the property $A$, and $\left(\mathrm{H}_{5}\right)$ implies that $E(G)$ has the transitivity property. Now, we will focus on the actual contraction property of the operator $T$. To this end, observe that by $\left(\mathrm{H}_{1}\right)$, for all $t \in[0,1]$ and for all $u, v \in C[0,1]$ such that $(u, v) \in E(G)$, we have

$$
\begin{aligned}
|T(u)(t)-T(v)(t)|= & \mid \frac{n t^{n-1}}{\left(n-\eta^{n}\right) \Gamma(\alpha)} \int_{0}^{\eta} \int_{0}^{s}(s-\tau)^{\alpha-1}(f(\tau, u(\tau))-f(\tau, v(\tau))) d \tau d s \\
& -\frac{n t^{n-1}}{\left(n-\eta^{n}\right) \Gamma(\alpha)} \int_{0}^{1}(1-s)^{n-\alpha-1}(f(\tau, u(s))-f(\tau, v(s))) d s \\
& +\frac{1}{\Gamma(\alpha)} \int_{0}^{t}(t-s)^{\alpha-1}(f(s, u(s))-f(s, v(s))) d s \mid \\
\leq & \frac{n t^{n-1}}{\left(n-\eta^{n}\right) \Gamma(\alpha)} \int_{0}^{\eta} \int_{0}^{s}|s-\tau|^{\alpha-1}|f(\tau, u(\tau))-f(\tau, v(\tau))| d \tau d s \\
& +\frac{n t^{n-1}}{\left(n-\eta^{n}\right) \Gamma(\alpha)} \int_{0}^{1}|1-s|^{\alpha-1}|f(s, u(s))-f(s, v(s))| d s \\
& +\frac{1}{\Gamma(\alpha)} \int_{0}^{t}|t-s|^{\alpha-1}|f(s, u(s))-f(s, v(s))| d s \\
\leq & \frac{n K_{1} t^{n-1}}{\left(n-\eta^{n}\right) \Gamma(\alpha)} \int_{0}^{\eta} \int_{0}^{s}|s-\tau|^{\alpha-1} \phi(|u(\tau)-v(\tau)|) d \tau d s \\
& +\frac{n K_{1} t^{n-1}}{\left(n-\eta^{n}\right) \Gamma(\alpha)} \int_{0}^{1}|1-s|^{\alpha-1} \phi(|u(s)-v(s)|) d s \\
& +\frac{K_{1}}{\Gamma(\alpha)} \int_{0}^{t}|t-s|^{\alpha-1} \phi(|u(s)-v(s)|) d s .
\end{aligned}
$$

That is,

$$
|T(u)(t)-T(v)(t)| \leq c_{0} K_{1} \phi\left(\|u-v\|_{\infty}\right),
$$

where

$$
\begin{aligned}
c_{0}= & \frac{n}{\left(n-\eta^{n}\right) \Gamma(\alpha)} \sup _{t \in(0,1)}\left(\int_{0}^{\eta} \int_{0}^{s}(s-\tau)^{\alpha-1} d \tau d s+\int_{0}^{1}(1-s)^{\alpha-1} d s\right. \\
& \left.+\frac{n-\eta^{n}}{n} \int_{0}^{t}(t-s)^{\alpha-1} d s\right) .
\end{aligned}
$$

Simple calculations give

$$
c_{0}=\frac{n}{\left(n-\eta^{n}\right) \Gamma(\alpha)}\left(\frac{\eta^{\alpha+1}}{\alpha(\alpha+1)}+\frac{2 n-\eta^{n}}{\alpha n}\right)=\frac{1}{\Gamma(\alpha+2)}\left[\frac{n \eta^{\alpha+1}+(\alpha+1)\left(2 n-\eta^{n}\right)}{\left(n-\eta^{n}\right)}\right] .
$$

By $\left(\mathrm{H}_{1}\right)$, we have $K_{1} \leq \frac{1}{c_{0}}$. We then arrive at

$$
|T(u)(t)-T(v)(t)| \leq \phi\left(\|u-v\|_{\infty}\right):=\phi(d(u, v)) .
$$


Using the fact that $\phi(r)<r$ for all $r \in(0,1]$, we may define $h: C[0,1] \times C[0,1] \rightarrow[0,1]$ by

$$
h(u, v)= \begin{cases}\frac{\phi(d(u, v))}{d(u, v)} & \text { if } u \neq v \\ 0 & \text { if } u=v\end{cases}
$$

At this point, all the conditions of Theorem 10 are satisfied. Therefore, there exists $u^{*} \in$ $C[0,1]$ such that $T u^{*}=u^{*}$ as required.

Note that in the case $n=2$, simple calculation gives

$$
K_{1}=\frac{\left(2-\eta^{2}\right) \Gamma(\alpha+2)}{2 \eta^{\alpha+1}+(\alpha+1)\left(4-\eta^{2}\right)}
$$

In fact, it is easy to see that $\frac{\Gamma(\alpha+2)}{5+3 \alpha} \leq K_{1}$. Furthermore, by setting $E(G)=\{(u, v) \in C[0,1] \times$ $C[0,1]: \xi(u(t), v(t)) \geq 0, \forall t \in[0,1]\}$ and assuming its transitivity property, where $\xi$ is as defined in the following corollary, we obtain that our result coincides with Theorem 4.1 in [11].

\section{Corollary 13 Suppose that the following conditions hold.}

$\left(H_{1}\right)$ There exist $\xi: \mathbb{R}^{2} \rightarrow \mathbb{R}$ and $\phi \in \Phi$ with $\phi(r)<r$ for each $r \in(0,1]$ such that, for all $t \in[0,1]$ and for all $u, v \in C[0,1]$ with $\xi(u(s), v(s)) \geq 0$ for every $s \in[0,1]$,

$$
|f(t, u(t))-f(t, v(t))| \leq \frac{\Gamma(\alpha+2)}{5+3 \alpha} \phi(|u(t)-v(t)|)
$$

$\left(H_{2}\right)$ There exists $u_{0} \in C[0,1]$ such that $\xi\left(u_{0}(t), T u_{0}(t)\right) \geq 0$ for all $t \in[0,1]$;

$\left(H_{3}\right)$ For all $u, v \in C[0,1]$,

$$
\xi(u(t), v(t)) \geq 0, \quad \forall t \in[0,1] \quad \text { implies } \quad \xi(T u(t), T v(t)) \geq 0, \quad \forall t \in[0,1]
$$

$\left(H_{4}\right)$ Let $\left\{u_{n}\right\}$ be a sequence in $C[0,1]$ such that $u_{n} \rightarrow u \in C[0,1]$. Let, for all $t \in[0,1]$,

$$
\begin{aligned}
& \xi\left(u_{n}(t), u_{n+1}(t)\right) \geq 0, \quad \forall t \in[0,1], \forall n \in \mathbb{N} \\
& \quad \text { imply } \xi\left(u_{n}(t), u(t)\right) \geq 0, \quad \forall t \in[0,1], \forall n \in \mathbb{N} ;
\end{aligned}
$$

$\left(H_{5}\right)$ For all $u, v, w \in C[0,1]$,

$$
\xi(u(t), v(t)), \xi(v(t), w(t)) \geq 0, \quad \forall t \in[0,1] \quad \text { implies } \quad \xi(u(t), w(t)) \geq 0, \quad \forall t \in[0,1]
$$

Then, for $1<\alpha \leq 2$, the BVP

$$
\left({ }^{c} D^{\alpha} y\right)(t)=f(t, y(t)), \quad t \in[0,1],
$$

with the boundary conditions

$$
y(0)=0 \quad \text { and } \quad y(1)=\int_{0}^{\eta} y(s) d s
$$

where $\eta \in[0,1]$, has at least one solution $u^{*} \in C[0,1]$. 
In addition, one can see that when $E(G)=C[0,1] \times C[0,1]$, conditions $\left(\mathrm{H}_{1}\right)-\left(\mathrm{H}_{5}\right)$ can be reduced to the following condition.

$\left(\mathrm{H}_{1}^{*}\right)$ For all $t \in[0,1]$ and for all $u, v \in C[0,1]$, there exists $\phi \in \Phi$ with $\phi(r)<r$ for all $r \in(0,1]$ such that

$$
|f(t, u(t))-f(t, v(t))| \leq K_{1} \phi(|u(t)-v(t)|),
$$

where the constant $K_{1}$ satisfies

$$
K_{1} \leq \frac{\left(n-\eta^{n}\right) \Gamma(\alpha+2)}{n \eta^{\alpha+1}+(\alpha+1)\left(2 n-\eta^{n}\right)}
$$

In this case, Theorem 12 also gives the following corollary.

Corollary 14 Suppose that condition $\left(H_{1}^{*}\right)$ holds. Then BVP (8)-(9) has at least one solution $u^{*} \in C[0,1]$.

We end this section with the following example.

Example 2 Let $g \in C[0,1]$. Consider the fractional differential equation

$$
\left({ }^{c} D^{\alpha} y\right)(t)=L \sqrt{t}(y(t)+g(t)), \quad t \in[0,1]
$$

with the boundary conditions

$$
y(0)=y^{\prime}(0)=\cdots=y^{(n-1)}(0)=0 \quad \text { and } \quad y(1)=0 .
$$

Observe that $\eta=0$, and $f(t, y(t))=L \sqrt{t}(y(t)+g(t))$. In order to obtain the existence result, we compute

$$
K_{1}=\frac{\Gamma(\alpha+2)}{2(\alpha+1)}
$$

Moreover, note that

$$
|f(t, u(t))-f(t, v(t))|=L \sqrt{t}|u(t)-v(t)| \leq 2 L \phi(|u(t)-v(t)|),
$$

where $\phi(t)=\frac{t}{2}$. By direct computations, we see that condition $\left(\mathrm{H}_{1}^{*}\right)$ holds when $2 L<\frac{\Gamma(\alpha+2)}{2(\alpha+1)}$. Therefore, the conclusion of Corollary 14 applies and, consequently, BVP (10) has at least one solution in $C[0,1]$ for all $L<\frac{\Gamma(\alpha+2)}{4(\alpha+1)}$.

\section{Numerical experiments}

In the last part, we note that the iterative approach can be used to study numerical solutions for the fractional BVP. This is the well-known Picard iterative method

$$
y_{k+1}=T y_{k}, \quad k=0,1,2,3, \ldots,
$$


which can be considered as $f \equiv I$ and $g \equiv T$ in our main results. Here, we apply the iterative method to solve and compare the approximate solutions with their exact solutions. In order to identify the method, we first establish the correctional function for BVP (8) as

$$
\begin{aligned}
y_{k+1}(t)= & \frac{n t^{n-1}}{\left(n-\eta^{n}\right) \Gamma(\alpha)} \int_{0}^{\eta} \int_{0}^{s}(s-\tau)^{\alpha-1} f\left(\tau, y_{k}(\tau)\right) d \tau d s \\
& -\frac{n t^{n-1}}{\left(n-\eta^{n}\right) \Gamma(\alpha)} \int_{0}^{1}(1-s)^{\alpha-1} f\left(s, y_{k}(s)\right) d s \\
& +\frac{1}{\Gamma(\alpha)} \int_{0}^{t}(t-s)^{\alpha-1} f\left(s, y_{k}(s)\right) d s .
\end{aligned}
$$

Starting from the initial point $y_{0}$, the successive approximate solutions can be obtained by calculating the integral appeared in equation (11). Occasionally, it might be difficult to calculate the integral directly due to the nonlinearity of $f(t, \cdot)$.

According to [32], we shall present an explicit algorithm for solving an approximate solution of the integral via the operator $T$ defined above. For the numerical computations, the interval $[0,1]$ is partitioned into $N$ subintervals. Let $Z_{0}$ be the uniform partition scale of the interval $[0,1]$ by the length $\Delta t=\frac{1}{N}$ and $t_{i}=(i-1) \Delta t$. For convenience, we let $t_{i}^{*}=\frac{t_{i+1}+t_{i}}{2}$, for $i=0,1,2, \ldots, N$. Then we obtain that

$$
\begin{aligned}
\int_{0}^{1}(1-s)^{\alpha-1} f\left(s, y_{k}(s)\right) d s & =\sum_{i=1}^{N} \int_{t_{i}}^{t_{i+1}}(1-s)^{\alpha-1} f\left(s, y_{k}(s)\right) d s \\
& \approx \Delta t \sum_{i=1}^{N}\left(1-t_{i}^{*}\right)^{\alpha-1} f\left(t_{i}^{*}, y_{k}\left(t_{i}^{*}\right)\right) .
\end{aligned}
$$

Moreover, for $t_{j} \in Z_{0}$, we see that

$$
\begin{aligned}
\int_{0}^{t_{j}}\left(t_{j}-s\right)^{\alpha-1} f\left(s, y_{k}(s)\right) d s & =\sum_{i=1}^{j-1} \int_{t_{i}}^{t_{i+1}}\left(t_{j}-s\right)^{\alpha-1} f\left(s, y_{k}(s)\right) d s \\
& \approx \Delta t \sum_{i=1}^{j-1}\left(t_{j}-t_{i}^{*}\right)^{\alpha-1} f\left(t_{i}^{*}, y_{k}\left(t_{i}^{*}\right)\right) .
\end{aligned}
$$

For the first term in the right-hand side of equation (11), we let $\eta=t_{p}+\epsilon$, where $0 \leq \epsilon<t_{p+1}$. Consider

$$
\begin{aligned}
\int_{0}^{\eta} & \int_{0}^{s}(s-\tau)^{\alpha-1} f\left(\tau, y_{k}(\tau)\right) d \tau d s \\
= & \sum_{i=1}^{p}\left[\int_{t_{i}}^{t_{i+1}} \int_{0}^{s}(s-\tau)^{\alpha-1} f\left(\tau, y_{k}(\tau)\right) d \tau d s\right] \\
& +\int_{t_{p}}^{t_{p}+\epsilon} \int_{0}^{s}(s-\tau)^{\alpha-1} f\left(\tau, y_{k}(\tau)\right) d \tau d s \\
\approx & \Delta t \sum_{i=1}^{p}\left[\int_{0}^{t_{i}^{*}}\left(t_{i}^{*}-\tau\right)^{\alpha-1} f\left(\tau, y_{k}(\tau)\right) d \tau\right]+ \\
& +\epsilon \int_{0}^{t_{p+1}}\left(t_{p+1}-\tau\right)^{\alpha-1} f\left(\tau, y_{k}(\tau)\right) d \tau
\end{aligned}
$$




$$
\begin{aligned}
& \approx \Delta t \sum_{i=1}^{p}\left[\sum_{j=1}^{i-1}\left(\int_{t_{j}}^{t_{j+1}}\left(t_{i}^{*}-\tau\right)^{\alpha-1} f\left(\tau, y_{k}(\tau)\right) d \tau\right)\right. \\
& \left.+\Delta t \int_{t_{i}}^{t_{i}^{*}}\left(t_{i}^{*}-\tau\right)^{\alpha-1} f\left(\tau, y_{k}(\tau)\right) d \tau\right] \\
& +\epsilon \sum_{i=1}^{p}\left[\int_{t_{i}}^{t_{i+1}}\left(t_{p+1}-\tau\right)^{\alpha-1} f\left(\tau, y_{k}(\tau)\right) d \tau\right] \\
& \approx(\Delta t)^{2} \sum_{i=1}^{p}\left[\sum_{j=1}^{i-1}\left(\left(t_{i}^{*}-t_{j}^{*}\right)^{\alpha-1} f\left(t_{j}^{*}, y_{k}\left(t_{j}^{*}\right)\right)\right)\right. \\
& \left.+(\Delta t)^{2}\left(t_{i}^{*}-t_{i}^{* *}\right)^{\alpha-1} f\left(t_{i}^{* *}, y_{k}\left(t_{i}^{* *}\right)\right)\right] \\
& +\epsilon \Delta t \sum_{i=1}^{p}\left[\left(t_{p+1}-t_{i}^{*}\right)^{\alpha-1} f\left(t_{i}^{*}, y_{k}\left(t_{i}^{*}\right)\right)\right],
\end{aligned}
$$

where the term $y_{k}\left(t_{i}^{* *}\right)$ can be estimated as

$$
y_{k}\left(t_{i}^{* *}\right) \approx \frac{y_{k}\left(t_{i}\right)+y_{k}\left(t_{i}^{*}\right)}{2} \approx \frac{3 y_{k}\left(t_{i}\right)+y_{k}\left(t_{i+1}\right)}{4}
$$

and $t_{i}^{* *}=\frac{t_{i}+t_{i}^{*}}{2}$. By using the values of $y_{k}(t)$, for all $t \in Z_{0}$, we can repeatedly calculate $y_{k+1}(t)$ for $k=0,1,2, \ldots$.

Here, the steps for computing the numerical solution $y_{k+1}$ with increasing $k$ are briefly provided as follows.

- Step 1. Input initial guess $y_{0}(t)$, the uniform length $\Delta t=\frac{1}{N}$, the accuracy goal $\delta$, and the maximum number of iteration $T_{\max }$.

- Step 2. Let $k=1$. Compute

$$
\begin{aligned}
I_{1}= & \Delta t \sum_{i=1}^{N}\left(1-x_{i}^{*}\right)^{\alpha-1} f\left(t_{i}^{*}, y_{k}\left(t_{i}^{*}\right)\right), \\
I_{2}= & (\Delta t)^{2} \sum_{i=1}^{p}\left[\sum_{j=1}^{i-1}\left(\left(t_{i}^{*}-t_{j}^{*}\right)^{\alpha-1} f\left(t_{j}^{*}, y_{k}\left(t_{j}^{*}\right)\right)\right)+(\Delta t)^{2}\left(t_{i}^{*}-t_{i}^{* *}\right)^{\alpha-1} f\left(t_{i}^{* *}, y_{k}\left(t_{i}^{* *}\right)\right)\right] \\
& +\epsilon \Delta \sum_{i=1}^{p}\left[\left(t_{p+1}-t_{i}^{*}\right)^{\alpha-1} f\left(t_{i}^{*}, y_{k}\left(t_{i}^{*}\right)\right)\right] .
\end{aligned}
$$

- Step 3. Update the numerical solution $y_{k+1}(t)$ on $Z_{0}$ as for $j=0,1,2, \ldots, N d o$

$$
y_{k+1}\left(t_{j}\right)=\frac{n t_{j}^{n-1}}{\left(n-\eta^{n}\right) \Gamma(\alpha)}\left(I_{2}-I_{1}\right)+\frac{\Delta t}{\Gamma(\alpha)} \sum_{i=1}^{j}\left(t_{j}-t_{i}^{*}\right)^{\alpha-1} f\left(t_{i}^{*}, y_{k}\left(t_{i}^{*}\right)\right) .
$$

end for

- Step 4. If the maximum error $\left\|y_{k+1}-y_{k}\right\|_{\infty}<\delta\left(k \leq T_{\max }\right)$, then $y_{k+1}(t)$ is the approximate solution of BVP (8) - (9) on [0,1]. Otherwise, increase $k$ by 1 and go to Step 2. 
Table 1 Numerical comparison of the errors in Example 3

\begin{tabular}{rlllll}
\hline \multicolumn{5}{c}{$N$} & \multicolumn{5}{l}{ Number of iteration } \\
\cline { 2 - 6 } & 2 & 4 & 6 & 8 & 10 \\
\hline 1250 & $6.9316 \times 10^{-6}$ & $7.3742 \times 10^{-7}$ & $7.3739 \times 10^{-7}$ & $7.3739 \times 10^{-7}$ & $7.3739 \times 10^{-7}$ \\
2500 & $6.4920 \times 10^{-6}$ & $2.6084 \times 10^{-7}$ & $2.6080 \times 10^{-7}$ & $2.6080 \times 10^{-7}$ & $2.6080 \times 10^{-7}$ \\
5000 & $6.3372 \times 10^{-6}$ & $9.2264 \times 10^{-8}$ & $9.2226 \times 10^{-8}$ & $9.2226 \times 10^{-8}$ & $9.2226 \times 10^{-8}$ \\
10,000 & $6.2826 \times 10^{-6}$ & $3.2649 \times 10^{-8}$ & $3.2611 \times 10^{-8}$ & $3.2611 \times 10^{-8}$ & $3.2611 \times 10^{-8}$ \\
20,000 & $6.2633 \times 10^{-6}$ & $1.1569 \times 10^{-8}$ & $1.1531 \times 10^{-8}$ & $1.1531 \times 10^{-8}$ & $1.1531 \times 10^{-8}$ \\
\hline
\end{tabular}

In the succeeding part, we present several numerical experiments to support the capability of the proposed algorithm. The computer programs are written in MATLAB. Through the simulations, the accuracy goal is set to be $10^{-16}$ and maximum iteration $T_{\max }=100$. The purpose of the first example is to provide a numerical study of the solution in the special case $\alpha=2.5$ of Example 2. Additionally, the numerical solutions are compared with an analytic solution in order to examine the efficiency of the present algorithm. We also estimate the rate of convergence by using two numerical solutions with different length of discretization $N_{1}$ and $N_{1} / 2$, corresponding to the formula

$$
\text { Rate }=\log _{2}\left(\| \text { Error }_{1}\left\|_{\infty} /\right\| \text { Error }_{2} \|_{\infty}\right)
$$

which has been widely used (see, for example, [33-37]).

Example 3 Consider the fractional differential equation

$$
\left({ }^{c} D^{2.5} y\right)(t)=\frac{\sqrt{t}}{4 \Gamma(0.5)}\left(y(t)-t^{3}+t^{2}+48\right), \quad t \in[0,1]
$$

with the boundary conditions

$$
y(0)=y^{\prime}(0)=0 \quad \text { and } \quad y(1)=0 .
$$

Here, we note that $g(t)=-t^{3}+t^{2}+48$ and

$$
L=\frac{1}{4 \Gamma(0.5)} \approx 0.14104<\frac{\Gamma(4.5)}{4 \Gamma(3.5)} \approx 0.8308:=K_{1}
$$

in Example 2. In this situation, we immediately obtain that the BVP has at least one solution in $C[0,1]$. In fact, it is not difficult to see that $y(t)=t^{3}-t^{2}$ is a solution to the problem, which is helpful for checking the accuracy of the proposed numerical schemes. With $u_{0}(t)=t$ and $N=1250,2500,5000,10,000$, and 20,000, we apply the numerical schemes for solving this problem. Table 1 shows the errors in various values of iteration $k=2,4,6,8$, and 10 with different $N$. The results suggest that the accuracy is slightly improved as $N$ increases. The error obtained drops significantly after the two-round iteration; however, the iteration number does not significantly impact the accuracy of the schemes after the four-round iteration. The numerical solutions for $k=1,2,5$, and 10 with $N=2500$ are plotted in Fig. 1(a), and the maximum errors are presented in Fig. 1(b). Additionally, Table 2 presents the number of iteration which reaches the accuracy goal $\epsilon=10^{-16}$ and the rate of convergence. From the table it can be observed that the convergence rate of the numerical algorithm seems to be approximately 1.5, which is illustrated in Fig. 2. 


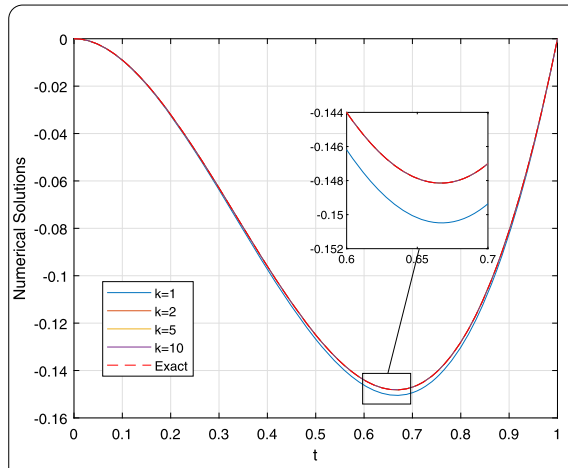

(a) Numerical solutions when $k=1,2,5,10$.

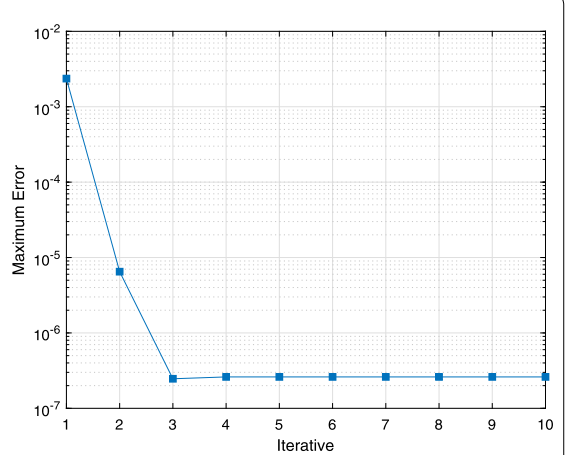

(b) Maximum error

Figure 1 Numerical simulations for Example 3 using $N=2500$

Table 2 Number of iteration and rate of convergence for Example 3

\begin{tabular}{rlll}
\hline$N$ & Number of iteration & $\|$ Error $\|_{\infty}$ & Rate \\
\hline 1250 & 8 & $1.0304 \times 10^{-6}$ & - \\
2500 & 8 & $2.6080 \times 10^{-7}$ & 1.4995 \\
5000 & 8 & $9.2226 \times 10^{-8}$ & 1.4997 \\
10,000 & 8 & $3.2611 \times 10^{-8}$ & 1.4998 \\
20,000 & 8 & $1.1531 \times 10^{-8}$ & 1.4999 \\
\hline
\end{tabular}

Figure 2 The order of approximation in terms of $\Delta t=1 / \mathrm{N}$ using $N=1250,2500,5000,10,000$, and 20,000

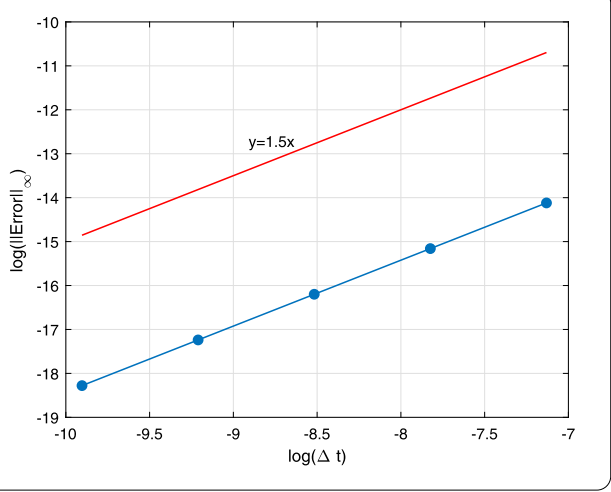

Example 4. Consider the fractional differential equation

$$
\left({ }^{c} D^{3.5} y\right)(t)=L(\arctan y(t)+\sin t), \quad t \in[0,1]
$$

with the boundary conditions

$$
y(0)=y^{\prime}(0)=y^{\prime \prime}(0)=0 \quad \text { and } \quad y(1)=\int_{0}^{1} y(s) d s .
$$

Observe that $\alpha=3.5, \eta=1$, and $f(t, y(t))=L(\arctan y(t)+\sin t)$. In order to obtain the existence result, we compute

$$
K_{1}=\frac{3 \Gamma(5.5)}{4+(4.5) 7} \approx 4.4233
$$




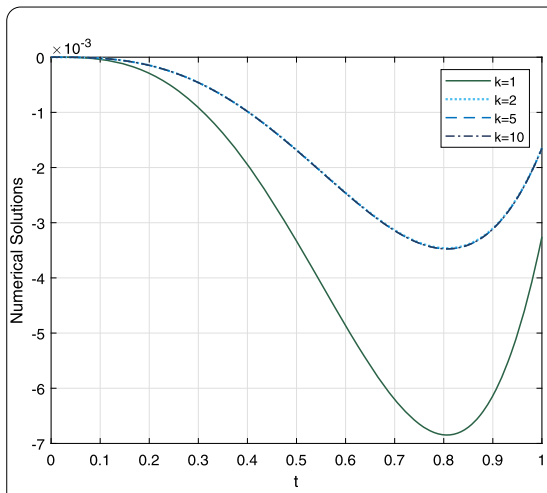

(a) $L=1$

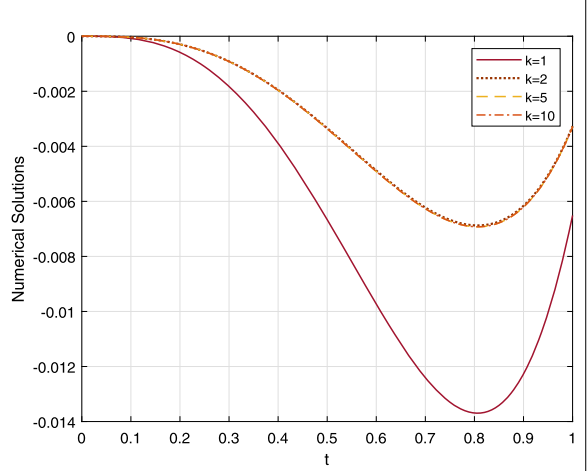

(b) $L=2$

Figure 3 Numerical simulations for Example 4

and

$$
|f(t, u(t))-f(t, v(t))|=L|\arctan u(t)-\arctan v(t)| \leq 2 L \phi(|u(t)-v(t)|),
$$

where $\phi(t)=\frac{t}{2}$. By direct computations, we see that condition $\left(\mathrm{H}_{1}^{*}\right)$ holds when $2 L<$ 4.4233. Therefore, the conclusion of Corollary 14 applies and, consequently, BVP (13) has at least one solution in $C[0,1]$ for all $L<2.2117$. Here, we provide numerical simulations when $L=1$ and 2. It is worth mentioning that our simulations are carried out under the setting $N=5000$ with $u_{0}(t)=t$. The numerical solutions for $k=1,2,5$, and 10 are plotted in Fig. 3, where the cases $L=1$ and $L=2$ are given in (a) and (b), respectively.

\section{Conclusions}

In this paper, we have studied $h-\phi$ contraction mappings with two metrics endowed with a directed graph and proved some existence criteria of common fixed points. By applying our main results, the existence of the solution for Caputo fractional boundary value problems of order $\alpha \in(n-1, n]$ with the integral boundary condition type, where $n \geq 2$ is an integer, is obtained. Besides, we have successfully constructed a Picard-based iterative strategy for solving certain types of Caputo fractional boundary value problems of order $\alpha \in(n-1, n]$. The present iterative algorithm is based on numerical integration, which produces a computationally cost-effective solver. The numerical experiments confirm that the proposed algorithm is robust and reliable. Moreover, the results suggest that the order of convergence is approximately 1.5 in the case of $\alpha=2.5$ as shown in Example 3 . Based on these findings, there is still a lot of space for future works, especially the details of the error analysis, rate of convergence, theoretical investigation, and the limitations of the present algorithm. However, it is worth noting that numerical results give a new aspect to study the solution behavior for other types of Caputo fractional boundary value problems.

Acknowledgements

This research is supported by Chiang Mai University and Faculty of Science, Chiang Mai University, Chiang Mai, Thailand. 
Availability of data and materials

Not applicable.

\section{Declarations}

\section{Competing interests}

The authors declare that they have no competing interests.

\section{Authors' contributions}

All authors contributed equally to the writing of this paper. All authors read and approved the final manuscript.

\section{Author details}

Advanced Research Center for Computational Simulation, Chiang Mai University, Chiang Mai, 50200, Thailand. ${ }^{2}$ Department of Mathematics, Faculty of Science, Chiang Mai University, Chiang Mai, 50200, Thailand. ${ }^{3}$ Centre of Excellence in Mathematics, CHE, Si Ayutthaya Rd., Bangkok, 10400, Thailand.

\section{Publisher's Note}

Springer Nature remains neutral with regard to jurisdictional claims in published maps and institutional affiliations.

Received: 6 June 2021 Accepted: 25 August 2021 Published online: 22 November 2021

\section{References}

1. Abdeljawad, T., Agarwal, R.P., Karapınar, E., Kumari, P.S.: Solutions of the nonlinear integral equation and fractional differential equation using the technique of a fixed point with a numerical experiment in extended $b$-metric space. Symmetry (2019). https://doi.org/10.3390/sym11050686

2. Adiguzel, R.S., Aksoy, U., Karapınar, E., Erhan, I.M.: On the solution of a boundary value problem associated with a fractional differential equation. Math. Methods Appl. Sci. (2020). https://doi.org/10.1002/mma.665

3. Adiguzel, R.S., Aksoy, U., Karapınar, E., Erhan, I.M.: On the solutions of fractional differential equations via Geraghty type hybrid contractions. Appl. Comput. Math. 20, 313-333 (2021)

4. Afshari, H., Atapour, M., Karapınar, E.: A discussion on a generalized Geraghty multi-valued mappings and applications. Adv. Differ. Equ. (2020). https://doi.org/10.1186/s13662-020-02819-2

5. Afshari, H., Kalantari, S., Baleanu, D.: Solution of fractional differential equations via $\alpha-\phi$-Geraghty type mappings. Adv. Differ. Equ. (2018). https://doi.org/10.1186/s13662-018-1807-4

6. Afshari, H., Kalantari, S., Karapınar, E.: Solution of fractional differential equations via coupled fixed point. Electron. J. Differ. Equ. 286, 1 (2015)

7. Afshari, H., Karapınar, E.: A discussion on the existence of positive solutions of the boundary value problems via $\psi$-Hilfer fractional derivative on b-metric spaces. Adv. Differ. Equ. (2020). https://doi.org/10.1186/s13662-020-03076-z

8. Fu, X.: Existence results for fractional differential equations with three-point boundary conditions. Adv. Differ. Equ. (2013). https://doi.org/10.1186/1687-1847-2013-257

9. Lazreg, J.E., Abbas, S., Benchohra, M., Karapınar, E.: Impulsive Caputo-Fabrizio fractional differential equations in b-metric spaces. Open Math. (2021). https://doi.org/10.1515/math-2021-0040

10. Adiguzel, R.S., Aksoy, U., Karapınar, E., Erhan, I.M.: Uniqueness of solution for higher-order nonlinear fractional differential equations with multi-point and integral boundary conditions. RACSAM (2021) https://doi.org/10.1007/s13398-021-01095-3

11. Karapınar, E., Abdeljawad, T., Jarad, F.: Applying new fixed point theorems on fractional and ordinary differential equations. Adv. Differ. Equ. (2019). https://doi.org/10.1186/s13662-019-2354-3

12. Marasi, H.R., Afshari, H., Daneshbastam, M., Zhai, C.B.: Fixed points of mixed monotone operators for existence and uniqueness of nonlinear fractional differential equations. J. Contemp. Math. Anal. (2017). https://doi.org/10.3103/S1068362317010022

13. Jachymski, J.: The contraction principle for mappings on a metric space with a graph. Proc. Am. Math. Soc. 136 1359-1373 (2008)

14. Alfuraidan, M.R.: The contraction principle for multivalued mappings on a modular metric space with a graph. Can. Math. Bull. (2016). https://doi.org/10.4153/CMB-2015-029-x

15. Alfuraidan, M.R.: Remarks on monotone multivalued mappings on a metric space with a graph. J. Inequal. Appl. (2015). https://doi.org/10.1186/s13660-015-0712-6

16. Alfuraidan, M.R., Khamsi, M.A.: Caristi fixed point theorem in metric spaces with a graph. Abstr. Appl. Anal. (2014). https://doi.org/10.1155/2014/303484

17. Alfuraidan, M.R.: Remarks on Caristi's fixed point theorem in metric spaces with a graph. Fixed Point Theory Appl. (2014). https://doi.org/10.1186/1687-1812-2014-240

18. Beg, I., Butt, A.R., Radojević, S.: The contraction principle for set valued mappings on a metric space with a graph. Comput. Math. Appl. 60, 1214-1219 (2010)

19. Bojor, F: Fixed point theorems for Reich type contractions on metric spaces with a graph. Nonlinear Anal. 75 3895-3901 (2012)

20. Afshari, H., Alsulami, H.H. Karapınar, E.: On the extended multivalued Geraghty type contractions. J. Nonlinear Sci. Appl. 9, 4695-4706 (2016)

21. Asadi, M., Karapınar, E., Kumar, A.: $\alpha-\psi$-Geraghty contractions on generalized metric spaces. J. Inequal. Appl. (2014). https://doi.org/10.1186/1029-242X-2014-423

22. Cho, S.H., Bae, J.S., Karapınar, E.: Fixed point theorems for $\alpha$-Geraghty contraction type maps in metric spaces. Fixed Point Theory Appl. (2013). https://doi.org/10.1186/1687-1812-2013-329 
23. Karapınar, E., A discussion on " $\alpha$ - $\psi$-Geraghty contraction type mappings". Filomat (2014). https://doi.org/10.2298/FIL1404761K

24. Karapınar, E., $\alpha-\psi$-Geraghty contraction type mappings and some related fixed point results. Filomat (2014). https://doi.org/10.2298/FIL1401037K

25. Karapınar, E., Alsulami, H., Noorwali, M.: Some extensions for Geraghty type contractive mappings. J. Inequal. Appl. (2015). https://doi.org/10.1186/s13660-015-0830-1

26. Karapınar, E., Pitea, A.: On $\alpha$ - $\psi$-Geraghty contraction type mappings on quasi-Branciari metric spaces. J. Nonlinear Convex Anal. 17, 1291-1301 (2014)

27. Karapınar, E., Samet, B.: A note on ' $\psi$-Geraghty type contractions'. Fixed Point Theory Appl. (2014). https://doi.org/10.1186/1687-1812-2014-26

28. Charoensawan, P., Atiponrat, W.: Common fixed point and coupled coincidence point theorems for Geraghty's type contraction mapping with two metrics endowed with a directed graph. Hindawi J. Math. (2017). https://doi.org/10.1155/2017/5746704

29. Martínez-Moreno, J., Sintunavarat, W., Cho, Y.J.: Common fixed point theorems for Geraghty's type contraction mappings using the monotone property with two metrics. Fixed Point Theory Appl. (2015). https://doi.org/10.1186/s13663-015-0426-y

30. Jungck, G.: Compatible mappings and common fixed points. Int. J. Math. Math. Sci. 9, 771-779 (1986)

31. Agarwal, R.P., O'Regan, D.: Fixed point theory for generalized contractions on spaces with two metrics. J. Math. Anal. Appl. 248, 402-414 (2000)

32. Phothi, S., Suebcharoen, T., Wongsaijai, B.: On nonlocal boundary value problems of nonlinear $n$ th-order $q$-difference equations. Adv. Differ. Equ. (2017). https://doi.org/10.1186/s13662-017-1203-5

33. Roache, P.J.: Verification and Validation in Computational Science and Engineering. Hermosa Publishers (1998)

34. Oberkampf, W.L., Trucano, T.G.: Verification and validation in computational fluid dynamic. Prog. Aerosp. Sci. 38, 209-273 (2002)

35. Sayevand, K., Jafari, H.: On systems of nonlinear equations: some modified iteration formulas by the homotopy perturbation method with accelerated fourth- and fifth-order convergence. Appl. Math. Model. 40, 1467-1476 (2016)

36. Wongsaijai, B., Sukantamala, N., Poochinapan, K.: A mass-conservative higher-order ADI method for solving unsteady convection-diffusion equations. Adv. Differ. Equ. (2020). https://doi.org/10.1186/s13662-020-02885-6

37. Wongsaijai, B., Charoensawan, P., Chaobankoh, T., Poochinapan, K.: Advance in compact structure-preserving manner to the Rosenau-Kawahara model of shallow-water wave. Math. Methods Appl. Sci. 44, 7048-7064 (2021)

\section{Submit your manuscript to a SpringerOpen ${ }^{\circ}$ journal and benefit from:}

- Convenient online submission

- Rigorous peer review

- Open access: articles freely available online

- High visibility within the field

- Retaining the copyright to your article

Submit your next manuscript at $\gg$ springeropen.com 